\title{
Federalismo e Desenvolvimento Urbano
}

\author{
Professor Mestre Benevenuto Santos (Direito UniFOA) - (Direito - UFF) - (Direito \\ Ambiental. Pós Graduação Gama Filho) \\ benevenutofss@uol.com.br
}

\section{Resumo}

Falar em federalismo significa discutir parâmetros de ação estatal, executiva e legislativa, pelas esferas político-administrativas existentes. Contudo, isto não significa exclusão, ou impedimento, de ações compartilhadas entre as esferas governamentais envolvidas. Este talvez seja um dos maiores transtornos para os agentes políticos: garantir a impessoalidade nas escolhas realmente importantes e ditadas pela imperiosa necessidade do interesse coletivo. Complica-se esta situação quando a Constituição Federal não estabelece os limites de atuação de cada ente estatal, gerando uma superposição de interesses justificados pela própria predominância do interesse tutelado. Em espaços urbanos de alta concentração demográfica isto sempre ocorre. Neste trabalho, podemos delinear elementos que auxiliarão os estudos das regiões metropolitanas na estrutura do federalismo brasileiro.

Palavras Chaves: Federalismo; Competência; Região Metropolitana.

\section{Introdução}

A repartição de competências constitucionais entre os vários entes federativos é sempre um debate provocado por circunstancias políticas que se manifestam pelas divergências entre os atores envolvidos.

Quando se trata da titularidade de serviços, este debate vem acompanhado de disputas entre as esferas governamentais - União, Estados-membros, Distrito Federal e Municípios. Este ponto é uma das faces das relações de poder que se estabelece entre os governos federal, estadual e municipal.

As lacunas constitucionais, da mesma forma, permitem que cada entidade federativa estabeleçam os seus interesses segundo as suas circunstâncias, seguindo impulsos políticos que colocam o tema, em sua importância e conseqüência, num plano que, seguramente, levará a uma solução nada agradável aos destinatários destes serviços públicos.

A possibilidade de angariar receitas públicas por intermédio de taxas ou tarifas é inoportuna e raramente vem ao debate como resultado da qualidade necessária à prestação do sistema.

O estudo da titularidade dos serviços públicos em regiões de alta concentração populacional têm um conteúdo importante na medida em que muitas questões importantes do nosso contexto federativo são levantadas, tais como habitação, infra-estrutura urbana, limpeza de vias e manutenção e preservação de recursos hídricos.

No arcabouço deste tema, a participação das entidades associativas, ambientais e acadêmicas descrevem a importância da existência de critérios de prestação do serviço, de participação social, na sua oferta do serviço e remuneração, que repercute na enorme 
parcela da população. A todos, é oportuno e extremamente salutar a proteção dos manancias hídricos, principalmente em regiões metropolitanas e aglomerações urbanas que terão, em curtíssimo espaço de tempo, escassez desta fonte.

O tema está delimitado pelo estudo dos traços federalistas de nosso sistema jurídico, até chegarmos ao foco principal, qual seja, a importância de ampliação do foro de propostas e soluções em regiões metropolitanas, do qual participem todas as entidades federativas.

\section{O Federalismo}

O federalismo pode ser entendido como uma forma de organizar o poder político e de estruturar o Estado, distinguível de outras formas como é o modelo do Estado unitário. Em termos gerais, o federalismo contém em sua organização política e administrativa pelo menos dois níveis de governo, cada qual com um determinado número de atribuições e de responsabilidades públicas, e uma autonomia política recíproca. Por sua vez, o Estado unitário condensa o poder político em uma só organização institucional. A diferença essencial entre estes dois modelos é que cada uma das partes conserva uma capacidade própria de reprodução política (autonomia) e atribuições que têm uma delimitação territorial.

Em princípio, um Estado unitário se caracteriza pela existência de um pólo único de poder. Mas não existe um único modelo de Estado unitário. A França, por exemplo, é um Estado unitário, contudo, com uma ampla transferência de competências para governo local $^{1}$

V

A existência de duas esferas de governo, e conseqüentemente centros autônomos de decisões políticas, dentro de um mesmo território é crucial para o conceito de federalismo. Juridicamente as esferas federal e estadual têm igual status. Cada uma tem atribuições e poderes concedidos pela Constituição federal, de modo que uma não invada, anule, ou vete a jurisdição ou operações da outra. Este é o motivo que faz do sistema federal um modelo complexo de governo. Não é possível estabelecer, por escrito, na Constituição Federal, limites claros e precisos ao poder federal e aos poderes estaduais. Sempre restam áreas sombrias, nas quais tanto uma esfera como outra podem considerar que têm direito de interferir e legislar. É grande o potencial de conflitos aí existente.

Para José Alfredo de Oliveira Baracho, a federação é uma técnica para dividir, sem romper, a soberania entre os Estados membros, tecnicamente falando:

O federalismo é uma divisão constitucional de poderes entre dois ou mais componentes dessa figura complexa que decorre da existência de um Estado que possa apresentar formas de distribuição das tarefas políticas e administrativas. $^{2}$

O federalismo se define assim por uma estrutura dual de organização do poder de um Estado, onde o fundamental é a natureza política das relações que se estabelecem entre cada uma das partes (níveis de governo), caracterizadas por sua autonomia e pela não subordinação. Sua essência é a estrutura institucional dual e a autonomia política que conservam as partes ${ }^{3}$. 
O modelo federativo implementado não segue um roteiro pré-determinado, sendo a expressão de Gilberto Bercovici ${ }^{4}$ aquela que melhor sintetiza este consenso:

Afinal, não existe um "modelo" de federalismo ideal, puro e abstrato, que englobe a variedade de organizações existentes nos Estados denominados federais. O que existe é uma série de soluções concretas, historicamente variadas, de organização do Estado, dentro de determinadas características comuns entendidas como necessárias a um regime federal.

O desenho da estrutura federativa deve levar em consideração diversos fatores que são impossíveis de serem relacionados sem se esquecer de algum. Uma característica importante do mundo atual é a sua complexidade.

Para Carl Schmitt, o pacto federal é um pacto de espécie singular, pelo que se trata de um pacto constitucional. É, por isso, um ato de Poder Constituinte. ${ }^{5}$

Nas palavras de Bercovici ${ }^{6}$ : “... num Estado federal a unidade é o resultado de um processo de integração, em que a autonomia não se limita a ser um objeto passivo (garantia), mas é, essencialmente, sujeito ativo na formação desta unidade estatal (participação)".

Conforme nos relata José Alfredo de Oliveira Baracho a idéia federal é apontada nas sociedades políticas mais antigas, apesar de o Estado federal, como conceito ou forma de organização só ter surgido com a Constituição Americana de $1787^{7}$. A história conceitual e social do federalismo remonta a séculos. Alguns autores remontam sua origem às tribos hebréias, às ligas entre cidades da Grécia antiga, limitando o conceito do federalismo a seu conteúdo etimológico enquanto "aliança" (do latim foedus) entre entes políticos para criar uma estrutura orgânica superior, geralmente motivada por fatores militares.

O federalismo é uma forma de governo, baseada em um certo modo de distribuir e de exercer o poder político numa sociedade, sobre um determinado território, que resulta, dentre outros objetivos, da necessidade de preservar a diversidade de culturas ou da constatação das origens diferenciadas da história e das tradições políticas dos EstadosMembros, necessitando, portanto, de um estatuto que garanta a autonomia local.

No modelo do federalismo, originalmente o Poder Legislativo é o que tenderia a ser dominante, sendo este integrado por duas câmaras, a primeira representando aos estados em termos de igualdade (o Senado), independentemente de suas dimensões sociais ou territoriais, e a segunda representando a população (Câmara de Representantes). Com esta fórmula se integrou o novo governo nacional - com funções e recursos limitados - e se preservou a autonomia dos governos dos estados.

No modo de ver de Nelson da Nóbrega Fernandes ${ }^{8}$, para que exista o equilíbrio federativo três pontos são essenciais:

a) O primeiro é que se evite a supremacia dos Estados ou da União na repartição das competências, o que levaria a situações de subordinação e de competição política entre os membros da federação.

b) $\mathrm{O}$ segundo ponto resolve teoricamente este primeiro problema, ao consagrar as competências de interesse geral à União e deixando para os Estados aqueles temas de interesse local. A possibilidade de redefinição do que é geral e do que é local permite a atualização do pacto federativo de acordo com as circunstâncias históricas.

c) O terceiro ponto prevê mecanismos de solução para as crises de competências entre os Estados e a União, garantido a ambos a igualdade política perante a Constituição. 
Para isto existe uma instância federal de justiça que, sendo a responsável em resolver divergências relativas à interpretação da Constituição, se constitui em árbitro dos conflitos de competências entre os Estados e a União.

\section{O Federalismo Norte-americano como fonte do federalismo brasileiro}

É fato reconhecido que o federalismo moderno surgiu com os Estados Unidos, cujo sistema de governo se caracterizou pela integração de um Estado nacional determinado e limitado em seus poderes pelo povo soberano, que é a fonte constitutiva tanto dos estados da federação como do Estado nacional, o qual quedou plasmado em um acordo formal, que é o documento constitucional.

O Estado Federal foi uma inovação posta em prática no contexto de formação e consolidação da independência dos Estados Unidos. A base jurídica da União Federal de Estados está na aceitação comum e soberana de uma Constituição que subordina todos os membros da União ${ }^{9}$.

Como qualquer sistema de organização estatal o Estado Federal americano surgiu e evoluiu segundo certas circunstâncias históricas. Uma classificação aceita é a que identifica alguns modelos deste federalismo: o federalismo dual e não-intervencionista e o federalismo cooperativo e intervencionista. O primeiro se desenvolveu até a década de 1920; o segundo dos anos 30 aos anos 70, quando a globalização criou condições para uma reedição atualizada do primeiro modelo.

\section{O Federalismo dualista}

A ordem federal então criada tinha por fundamento a divisão estanque e a separação vertical dos poderes estatais entre a União e Estados. Cada esfera de poder possuía suas competências fundadas diretamente na Constituição, devendo exercê-las sem qualquer interferência externa. O equilíbrio seria assegurado e mantido pela demarcação rigorosa das competências de cada instância governamental, com a União e os Estados encarando-se muitas vezes como adversários.

A organização do "federalismo dual e não intervencionista" gira em torno de uma diretriz, muito nítida no caso dos Estados Unidos, que busca um forte equilíbrio de poderes entre os Estados e a União. Contudo, mesmo ali, observa-se que a partir de meados do século XIX, a União, baseada em decisões da Suprema Corte, foi retirando dos Estados diversas competências relativas a assuntos econômicos. O sentido de tais medidas foi o de desregulamentar o mercado interno para a livre atuação das corporações norte-americanas que estavam em formação ${ }^{10}$. Para tanto foi suficiente extrair competências dos Estados e a União não legislar ou estabelecer controles sobre tais assuntos. Com isto se reafirmava o não-intervencionismo, mas, por outro lado, era enfraquecido o pólo estadual dentro do dualismo federalista. Prestigiava-se o laissez faire, laissez passer $^{11}$ ao mesmo tempo em que se buscavam características do estado unitário que facilitasse o capitalismo.

As atribuições exercidas pelo Governo Federal eram definidas como poderes

enumerados. Á medida em que a crise de 1929 exigia do Governo Federal medidas mais rápidas para solução dos impasses econômicos surgidos em função de manutenção de privilégios defendidas pelos vários setores econômicos e empresariais, ficou asseverado que a competência do Poder Central não estaria descrita nos mínimos detalhes na 
Constituição, sendo reconhecido os poderes necessários e apropriados para o efetivo exercício dos poderes expressos ${ }^{12}$, conhecida como a doutrina dos poderes implícitos.

Torna-se imperativo reafirmar que as características dos vários tipos de federalismo não podem ser consideradas como absolutas. O federalismo norte-americano é caracterizado pela atuação da Suprema Corte na sua configuração no decorrer do desenvolvimento histórico da nação.

Gilberto Bercovici descreve este posicionamento da Suprema Corte, que, nos primórdios da República Americana, liderada pelo Justice Marshall, buscou consolidar a União, reforçando seus poderes frentes às ex-Colônias, agora Estados-Membros: era o national federalism."13

Bernard Schwartz ${ }^{14}$, reforçando esta evolução da doutrina dos poderes implícitos, diz que "(...), é o traço mais característico do sistema americano - isto é, a imposição dos princípios do federalismo pelo Judiciário. Um estado federal é, necessariamente um estado legal par excellence". A Suprema Corte dos Estados Unidos, por meio do seu poder de revisão, exerce o papel de árbitro do sistema federal, estabelecendo os limites entre os poderes federais e estaduais ${ }^{15}$.

Com a depressão da economia dos Estados Unidos em decorrência da crise de 1929, houve a necessidade de intervenção do Estado na economia para que a crise fosse superada. A intervenção do Estado na economia ocorreu no governo Roosevelt e ficou conhecida como a política do New Deal. Esta política demandou uma grande atuação do governo federal. Foi quando a Suprema Corte alterou o federalismo dual e centrífugo que até então vigorava nos Estados Unidos, para o federalismo cooperativo e centrípeto, adequando a Constituição americana às demandas de ordem social e econômica.

\section{O Federalismo de cooperação}

A necessidade de intervenção do Estado para solucionar os problemas gerados com a depressão da década de 1930 que levou ao abandono do federalismo dualista nos Estados Unidos $^{16}$.

A partir do New Deal ocorreu uma transformação do federalismo norte-americano, modificando as relações entre o governo central e o governo dos Estados, moldando a segunda fase do federalismo americano. Houve uma perda relativamente grande de autonomia do Estados-membros com relação à União. As necessidades das populações estaduais e a impossibilidade do Estado resolver a questão fizeram com que fosse aceito a transferência de alguns poderes à União. Estas mudanças não aconteceram sem gerar atritos entre a União e certos Estados. Contudo, como ressalta Gilberto Bercovici:

Este fato não gerou nenhuma "ditadura federal”, nem se deve exclusivamente à política nacionalista de Roosevelt. Na realidade, os Estados perderam a capacidade de solucionar, isoladamente, os principais problemas econômico-sociais de suas populações, ao mesmo tempo em que a União construiu e consolidou um vasto e poderoso aparelho administrativo federal. ${ }^{17}$

O federalismo cooperativo surge do abandono das orientações liberais num capitalismo que se volta para o consumo de massas. As dimensões da crise levaram ao fortalecimento da União, que progressivamente foi absorvendo competências estaduais e, principalmente, interferindo nas relações sociais e nas regras do mercado. Especialmente 
depois do ano de 1937, as decisões da Suprema Corte deram amparo constitucional a atos praticados pelo governo federal que estabeleciam controles sobres as atividades econômicas, de modo a limitar os abusos do poder econômico, a exploração da pobreza e a especulação que obstaculizavam a recuperação do país.

\section{O Federalismo no Brasil}

Com a independência, ocorrida em 1822, em que pese a extensão do território e a diversidade cultural, o Brasil adotou o sistema unitário de estado. O país era dividido em Províncias que tinham seus "presidentes” nomeados pelo Imperador e que não podiam legislar sobre seus assuntos específicos. Esse unitarismo vigorou enquanto houve identificação do poder econômico com o poder político.

Proclamada a República, as antigas províncias transformaram-se em Estados e o federalismo da Constituição de 1891, moldado no federalismo dualista clássico, praticamente ignorou a cooperação entre União e entes federados. É representativo desta situação o artigo $5^{\circ}$ da primeira Constituição republicana que restringia o auxílio federal aos Estados exclusivamente nos casos de calamidade pública. Somente em 1897 essa concepção alargou-se e o Governo Federal regulamentou este artigo, especificando os casos possíveis em que os Estados poderiam receber auxílio da União (calamidades), tendo como requisito a solicitação formal do pedido, dependendo ainda, para que a ajuda fosse efetivada, de comprovação documentada de que os recursos disponíveis do Estado requerente foram totalmente exauridos sem êxito para debelar a calamidade que o atingiu. ${ }^{18}$

Apenas com a Constituição de 1934 foi instituído um tipo de federalismo que se pode denominar cooperativo, que de acordo com seu artigo $9^{\circ}$ :

É facultado à União e aos Estados celebrar acordos para a melhor coordenação e desenvolvimento dos respectivos serviços, e, especialmente, para a uniformização de leis, regras ou práticas, arrecadação de impostos, prevenção e repressão da criminalidade e permuta de informações.

O artigo 10, por sua vez, estabeleceu a repartição das competências concorrentes, dando ênfase à solidariedade entre a União e os entes federados. A Constituição de 1934 se baseou na Constituição de Weimar e definia a cooperação entre os entes federados em seus artigos 140 e 177.

Após a Segunda Grande Guerra o mundo mudou de face. O colapso da Bolsa de 1929, a grande depressão e os novos ventos trazidos pela Grande Guerra mudou a estrutura do Estado, colocando em cheque os pressupostos do Estado Liberal. No Brasil, não foi diferente, em 1946 foi promulgada uma nova Constituição que consolidou a estrutura cooperativa no federalismo brasileiro:

com grande ênfase na redução dos desequilíbrios regionais, favorecendo, apesar do reforço do poder federal, a cooperação e integração nacional. Foi neste período que a Questão Regional ganhou importância no debate político nacional, com a concepção de que a atuação estatal e o planejamento eram elementos essenciais para o desenvolvimento, de acordo com as diretrizes elaboradas pela CEPAL. Desde então, todas as constituições brasileiras têm a preocupação de tentar consagrar instrumentos para a superação das desigualdades regionais. ${ }^{19}$

Nessa época houve uma mudança estrutural na Política brasileira: a ampliação da participação popular aliada à urbanização e a industrialização crescente transformaram o país, marcando uma transição para a democracia de massas no país. 
A ênfase na cooperação e superação das desigualdades regionais foi reforçada pela restauração do federalismo brasileiro com a Constituição de 1988. Esta restauração da Federação foi vista por alguns autores como um ressurgimento do "federalismo estadualista”, sem, no entanto, a formação de um núcleo hegemônico de Estados como na Primeira República: "Este “federalismo estadualista” se caracterizaria pelo controle das bancadas de deputados federais pelos Governadores e pela competição predatória entre os Estados por mais recursos, por meio da guerra fiscal”" ${ }^{20}$.

A grande inovação foi a inclusão dos Municípios como integrantes da Federação. Foi previsto expressamente o Federalismo Cooperativo (art. 23), elencando uma série de matérias de competência comum entre os entes federados. Ressalte-se que o parágrafo único do artigo determina que haverá uma Lei complementar fixando as normas para cooperação entre os entes, visando o equilíbrio do desenvolvimento e do bem-estar em âmbito nacional, contudo, até hoje esta norma não foi elaborada.

O Federalismo Cooperativo se justifica plenamente pela integração entre os Estados-membros e a União para implementar as políticas públicas definidas na Constituição de 1988 e pelo tipo de Estado ali estruturado, sendo impossível aos Estadosmembros desenvolverem sozinhos estas políticas, necessitando da União para um tratamento uniforme dentro do país e para solução de conflitos interestaduais. ${ }^{21}$

\section{Descentralização e tendências do federalismo no Brasil contemporâneo.}

A tendência para um federalismo baseado em reconhecimento de direitos e de solidariedade entre partes tem sido gravemente dificultada pelo aprofundamento da dívida interna e externa. A incapacidade financeira dos Estados restringe severamente uma descentralização de competências porque simplesmente existem cada vez menos recursos para o exercício de todas elas, sobretudo, se considerarmos que é sobre a União que pesam os maiores custos dos ajustes estruturais.

A situação viabiliza o desenvolvimento de um federalismo "pragmático ou reativo"

porque tem sido cada vez menor a possibilidade ou necessidade de exprimir como idéia política fundamental os princípios de solidariedade e co-responsabilidade governamentais. Assim, a barganha federativa não requer nenhum revestimento de projeto nacional, estando cada vez mais subordinada ao jogo dos interesses privados contrariando os princípios constitucionais vigentes.

Em um Estado intervencionista, voltado para a implementação de políticas públicas, os Estados-membros não têm como analisar e decidir, originariamente, sobre inúmeros setores da atuação estatal, que necessitam de um tratamento uniforme em escala nacional. Isto ocorre principalmente com os setores econômico e social que exigem uma unidade de planejamento e direção. Antes, portanto, de o Estado Social estar em contradição com o Estado federal, o Estado Social influi de maneira decisiva no desenvolvimento do federalismo atual, sendo o federalismo cooperativo considerado como o federalismo adequado ao Estado Social.

Esta unidade de atuação não significa, necessariamente, centralização. Precisamos, antes de tudo, diferenciar centralização de homogeneização. Com a centralização há a concentração de poderes na esfera federal, debilitando os entes federados em favor do poder central. Já a homogeneização (Uniarisieurung, uniformização) é baseada na cooperação, pois se trata do processo de redução das desigualdades regionais em favor de 
uma progressiva igualação das condições sociais de vida em todo o território nacional. A homogeneização não é imposta pela União, mas é resultado da vontade de todos os membros da Federação ${ }^{22}$.

As tensões do federalismo contemporâneo, situadas basicamente entre a exigência da atuação uniformizada e harmônica de todos os entes federados e o pluralismo federal, são resolvidas em boa parte por meio da colaboração e atuação conjunta das diversas instâncias federais. A cooperação se faz necessária para que as crescentes necessidades de homogeneização não desemboquem na centralização. A virtude da cooperação é a de buscar resultados unitários e uniformizadores sem esvaziar os poderes e competências dos entes federados em relação à União, mas ressaltando a sua complementaridade.

O grande objetivo do federalismo, aparentemente e na atualidade, seria a busca da cooperação entre União e demais entes federados, equilibrando a descentralização federal com os imperativos da integração econômica nacional.

\section{O federalismo brasileiro e a estrutura de poder centralizada}

O federalismo centrípeto é aquele que se dirige para o centro, ou seja, em que há uma predominância de atribuições para União, uma centralização. O federalismo centrífugo é aquele que procura se afastar do centro, isto é, permite com que os Estados-Membros tenham maior autonomia financeira, administrativa, política e jurídica.

O que se busca é um equilíbrio que concilie integração e autonomia, entre a unidade e a diversidade regional e local, e, ao mesmo tempo, que seja um fortalecimento do País como todo, tendo em vista as relações internacionais e os objetivos internos. Analisando o federalismo que vigora no Brasil, verifica-se que é o federalismo centrípeto.

No caso do Brasil, a supremacia do poder federal é estabelecida de forma indireta, pois a Constituição Brasileira, embora mantenha a equivalência formal entre União e Estados-Membros ao distribuir as competências, demonstra de forma incontestável a supremacia do poder federal. Segundo Dallari ${ }^{23}$, esta supremacia é decorrente de duas causas. A primeira é que a enumeração de competências federais é ampla, abrangendo quase tudo o que é essencial em termos de direitos e deveres fundamentais, economia e finanças, bem como sobre a organização e ação política. A segunda causa é o fato da União ter competência para fixar regras gerais em matérias de competências estaduais.

A necessidade de coordenação deriva principalmente da separação de competências entre os entes da federação. No entanto, há outros fatores que transformam em obrigatória a necessidade de coordenação.

O primeiro dos fatores consiste no fato da repartição de competências ter como critério a distinção, implícita ou explícita, das matérias de interesse nacional ou local. O problema surge pelo fato destas matérias de interesse nacional e local se modificarem, conforme se altera o contexto história e a conjuntura do momento. O segundo fator é um consectário da repercussão direta ou indireta das decisões que cada ente da federação toma nos demais governos. $\mathrm{O}$ último fator consubstancia-se na necessidade de ação coordenada de todos os entes da federação no combate contra os problemas que são comuns a todos, como a inflação, recessão econômica, etc.

Com o federalismo cooperativo há uma alteração no conceito de autonomia, que passa a se medir menos pelas disposições jurídicas e pela defesa das barreiras constitucionais e mais pela capacidade de influência tanto no âmbito das negociações entre todos os entes da federação, como nas comissões freqüentemente consuetudinárias e 
segundo procedimentos que devem assegurar a igualdade entre os entes representados. Para um governo federado, a defesa da autonomia passa a depender de sua capacidade de negociação nos âmbitos que considera prioritário. Os atores mais influentes serão aqueles que possuírem a maior variedade de informação e que puderem se comunicar de forma simples com os demais atores.

Não há dúvida de que no federalismo cooperativo os entes federados perdem uma parcela de sua autonomia originária. No entanto, esta autonomia perdida não é confiscada pelo governo federal, porque, na realidade, as matérias de competência exclusiva ou privativa de competência do ente federal também são afetadas.

O federalismo cooperativo não exclui os conflitos de competência, as concorrências ou as duplicações de atividades entre os entes da federação, mas tenta reduzir o alcance destes problemas através de acordos políticos negociados. Não constitui uma etapa definitiva da história do federalismo, pois é suscetível de conhecer fases de centralização e descentralização.

\section{Autonomia municipal e federalismo}

O processo decisório em nível municipal sofreu grandes mudanças após a promulgação da Constituição de 1988, as quais têm profundas implicações para a relevância que este passou a ter na busca da autonomia municipal. Essa mudança se deve às modificações que transformaram os parâmetros do processo decisório local, especificamente as transformações sócio-econômicas, tanto no que se refere ao avanço da urbanização - uma modificação de caráter estrutural —, como mudanças conjunturais dadas pela crise e pela política econômica do Governo Federal no período pós-Constituinte.

As transformações sócio-econômicas influenciaram a gestão municipal no sentido de atender novas e crescentes demandas da população e podem ser classificadas em dois níveis distintos, a saber, estruturais e conjunturais. Como mudanças estruturais entende-se a intensificação do processo de urbanização, gerando por parte da população municipal um aumento de demandas por serviços e equipamentos sociais em saúde, habitação, saneamento e educação.

Como modificações conjunturais, trata-se da retração econômica gerada pela política recessiva do governo federal no pós-Constituinte, a qual teve implicações de duas ordens, basicamente. A primeira, junto à população, no acúmulo progressivo das suas demandas; A segunda, fazendo identificar a responsabilidade do município, uma vez que este se posiciona como o nível de mais próximo da população.

Desenhava-se assim uma situação na qual, apesar da Constituição destinar um maior aporte de recursos aos municípios, estes acabavam sendo, de fato, insuficientes em virtude da combinação aumento de demandas versus retração de recursos. Assim, em contrapartida a essa mesma retração da economia, havia um incremento das demandas por serviços e equipamentos públicos, gerando uma situação contraditória na qual o período conjuntural propiciava tanto uma maior escassez de recursos quanto uma maior demanda por eles.

Esta situação tornou-se particularmente agravada uma vez que a mesma Constituição que destinou maiores recursos aos municípios também lhes transferiu novas obrigações, em tese correspondentes à sua maior fatia no bolo tributário. Neste caso em particular, temos que as atribuições assumidas pelo Municípios não eram novas, mas apenas ampliadas, sendo, em algumas destas, exercidas com suporte de recursos federais, 
dentro de um ambiente de cooperação mútua, digna de um federalismo. Isto é o que ocorre com o Sistema Único de Saúde e com o Fundo da Desenvolvimento e Valorização do Magistério. Negar este fato, é fechar os olhos ao noticiário que vem sendo veiculado em toda mídia. Essas obrigações municipais determinadas pela Constituição de 1988, referentes a novas incumbências nas áreas de saúde e educação, são desempenhadas em caráter comum, devendo o Poder Federal estabelecer diretrizes e ações redistributivas.

Para que se possa ter uma idéia do que isto representa basta ter em conta o que a nova Carta determina em seu capítulo IV, intitulado “Dos Municípios”24:

“Artigo 30. Compete aos municípios: (...)

"V — organizar e prestar, diretamente ou sob regime de concessão ou permissão, os serviços públicos de interesse local, incluído o de transporte coletivo, que tem caráter essencial;

"VI — manter, com a cooperação técnica e financeira da União e do Estado, programas de educação pré-escolar e de ensino fundamental;

"VII — prestar, com a cooperação técnica e financeira da União e do Estado, serviços de atendimento à saúde da população; (...)”

Além das constantes situações de crise econômica, cabe lembrar que os municípios não alinhados à situação política, estadual ou federal, enfrentam dificuldades consideráveis no que se refere ao recebimento de crédito das agências financiadoras controladas por essas esferas de poder. Se a crise fiscal vivida pelo Estado brasileiro e a escassez generalizada de recursos por si mesmas já é são motivos para a redução dos financiamentos, e os recursos disponíveis para operações de crédito, o critério político-partidário para escolher que municípios receberão financiamentos, excluindo outros, agrava ainda mais a questão.

O processo de autonomização municipal está ligado à necessidade de que ocorram avanços no âmbito da interação dos representantes em nível local, Executivo e Legislativo, o que significa um aperfeiçoamento da democracia representativa.

Uma questão fundamental para o equilíbrio entre os níveis de governos é o grau de (des)centralização de poder. Os estados e municípios estão mais perto dos cidadãos, o que facilita não só a fiscalização popular dos atos públicos, como também permite uma colaboração de entidades civis na realização de objetivos públicos. O federalismo impede que toda ação pública fique sob a responsabilidade de um distante governo central.

\section{A repartição de competências no Brasil}

A sistemática para definição de competências e atribuições dos entes federativos no Brasil, consiste num elenco exaustivo das competências federais, permitindo-se a interpretação das competências implícitas ou abrangidas pelas determinações constitucionais expressas. Em seguida, a Constituição define algumas competências estaduais e municipais, que não são numerus clausus. Não há uma regra expressa de que os poderes remanescentes cabem ao Estado.

Observa-se que o critério de organização das competências são heterogêneos, ou seja, as competências são orientadas por critérios diversos. Para organização dos bens públicos utilizam-se critérios diferentes da discriminação de competências tributárias e assim por diante. 
Há competências comuns e competências privativas. Algumas competências são reservadas exclusivamente a um determinado ente e há aquelas que são atribuídas pela Constituição a todos entes federativos. Algumas dessas competências não são declaradas expressamente pela Constituição, sendo alvo de interpretação jurisprudencial.

$\mathrm{O}$ art. 21 da Constituição Brasileira contém um elenco de competências federais. O art. $25 \S 1^{\circ}$ dispõe incumbirem aos Estados as competências que não lhes sejam vedadas constitucionalmente. $\mathrm{O}$ art. 30, inc. V, determina que os Municípios organizem os serviços públicos de interesse local, fazendo alusão inclusive ao transporte coletivo.

Em outros artigos a Constituição aborda os serviços públicos de interesse comum a serem organizados conjuntamente ou mediante atuação coordenada entre as diversas órbitas da Federação, como os serviços de saúde, de assistência e de educação.

Contudo, o art. 25, § $3^{\circ}$, prevê que:

Os Estados poderão mediante lei complementar, instituir regiões metropolitanas, aglomerações urbanas e microrregiões, constituídas por agrupamentos de municípios limítrofes, para integrar a organização, o planejamento e a execução de funções públicas de interesse comum.

Ressalte-se que o art. 241 estabelece que:

A União, os Estados, o Distrito Federal e os Municípios disciplinarão por meio de lei os consórcios públicos e os convênios de cooperação entre os entes federados, autorizando a gestão associada de serviços públicos, bem como a transferência total ou parcial de encargos, serviços, pessoal e bens essenciais à continuidade dos serviços transferidos.

\section{Coordenação e repartição de competências.}

São nas competências concorrentes que a coordenação na repartição de poderes é manifestada. A União, o Estado e os municípios concorrem em uma mesma função, mas com âmbito e intensidade distintos. Cada ente federado decide, dentro de sua esfera de poderes, de maneira separada e independente, com a ressalva da prevalência do direito federal $^{25}$. Este tipo de repartição é o previsto pelo artigo 24 da Constituição de 1988.

Na há o que se falar de atuações isoladas dos entes federados. Cooperação significa que, nem a União, nem qualquer outro ente podem atuar sozinhos, mas as competências devem ser exercidas por todos conjuntamente com os demais. São nas denominadas competências comuns, dispostas no art. 23 da Magna Carta, na repartição de competências que a cooperação se revela. "Nas competências comuns, todos os entes da Federação devem colaborar para a execução das tarefas comuns, todos os entes da Federação devem colaborar para a execução das tarefas determinadas pela Constituição”. ${ }^{26}$ Frise-se que as responsabilidades também são comuns, uma vez que não existe supremacia de nenhuma das esferas de poder na execução destas tarefas, não podendo nenhum dos entes federados deixar de implementá-las, pois o custo político recairia sobre todas as esferas de governo. Existe dificuldade na atribuição de competências, diferenciando, as competências comuns das competências concorrentes e exclusivas, uma vez que a cooperação parte do pressuposto da estreita interdependência existente em inúmeras matérias e programas de interesse comum. Por isso, dificulta a sua atribuição exclusiva ou preponderante a um determinado ente.

Gilberto Bercovici anota que o interesse comum viabiliza a existência de um mecanismo unitário de decisão, no qual participam todos os integrantes da Federação. ${ }^{27}$ Existem dois momentos decisórios na cooperação. O primeiro se dá em nível federal, 
quando se determinam conjuntamente as medidas a serem adotadas, uniformizando-se a atuação de todos os poderes estatais competentes em determinada matéria. O segundo momento ocorre em nível estadual ou municipal, quando cada ente federado adapta a decisão tomada em conjunto às suas características e necessidades. Na cooperação, em geral, a decisão é conjunta, mas a execução se realiza de maneira separada, embora possa haver, também, uma atuação conjunta, especialmente no tocante ao financiamento das políticas públicas”.

Quem discrimina as competências dos entes federados é a Constituição. Fora dos casos expressamente previstos no texto constitucional, predomina o princípio da separação e independências no exercício das competências constitucionais. A cooperação obrigatória é definida pela Constituição, determinando que só poderá ser exercida de forma conjunta. Torna-se importante ressaltar que, as competências comuns do artigo 23 da Constituição, após sua regulamentação pela lei complementar prevista no parágrafo único do mesmo artigo, serão obrigatórias para a União e todos os entes federados. A lei complementar prevista não poderá retirar nenhum ente da titularidade das competências comuns, nem restringi-las.

Com a restauração do federalismo pela Constituição de 1988, as políticas de desenvolvimento regional devem ser elaboradas e implementadas dentro dos marcos do sistema federal, ou seja, com a coordenação e cooperação da União e todos os entes federados. Para tanto, é essencial que evitemos a concepção racionalista e artificial que vê o federalismo apenas como um problema de organização, tendo em vista o objetivo da otimização e da eficiência máxima da atuação estatal. Concepção tecnocrática esta que não leva em consideração os processos históricos da evolução e formação do Estado federal concreto.

\section{O Federalismo de Cooperação e as políticas de desenvolvimento urbano}

As cidades possuem, em quaisquer de suas escalas de crescimento, desafios próprios para garantir um quadro de políticas públicas permanentes e necessárias a uma boa qualidade de vida de seus cidadãos. As peculiaridades regionais e locais, com maior ou menor grau de intensidade, acarretam problemas intra-urbanos que afetam sua sustentabilidade, especialmente em questões como déficit de moradias adequadas, déficit de cobertura de saneamento ambiental, baixa qualidade de transporte público, além de toda marginalização social que surge com o crescimento demográfico.

É Importante tomar todas as medidas possíveis que evitem a insustentabilidade dos padrões de degradação dos recursos naturais, imprescindíveis para a economia e para o desenvolvimento urbano. Contudo, em termos ambientais e urbanos, algumas metas só poderão ser atingidas em longo prazo, desde que os entes federativos atuem em parceria, entre estes e com a sociedade, introduzindo políticas urbanas capazes de oferecer resultados gradualmente, apropriando-se das próprias experiências.

Os problemas relacionados com a gestão urbana, especificamente água e serviços públicos de saneamento devem ser inseridos no conceito de desenvolvimento urbano, promovendo uma gestão participativa eficaz do território. Não há como estabelecer um quadro de medidas governamentais, legislativas e administrativas, sem o estudo de soluções interligadas. 


\section{Aspectos regionais do federalismo - a urbanização e o federalismo}

A estrutura urbana formada no Brasil levou à concentração de sistemas polarizados, a eixos de ocupação urbana, da qual a metrópole é sua principal característica. Isso acentua a concentração da população urbana nas áreas metropolitanas e em aglomerações urbanas, reforçando os desequilíbrios de redes de cidades, recrudescendo problemas sociais, urbanos e ambientais nos grandes centros, sem esquecer que mesmo os investimentos necessários causam efeitos danosos à cidade sustentável. Necessário se faz uma reformulação na intervenção no território e nas áreas urbanas, conferindo importância ao planejamento do desenvolvimento regional, que podem se constituir em meio reestruturador das políticas voltadas para a transformação das cidades brasileiras. As cidades devem ser consideradas como parte integrantes das suas respectivas regiões e microrregiões, ${ }^{28}$ em função de condicionantes territoriais de sustentabilidade.

O perfil da demanda por serviços públicos essenciais, tomando por base os serviços de saneamento ambiental, guarda relação histórica com exclusão social e a segregação espacial e tem seus contornos definidos por fatores como:

a) a distribuição desigual do acesso aos serviços segundo faixas de renda da população;

b) a regionalização das carências, que configura as diferenças e as desigualdades entre as áreas centrais, intermediárias e periféricas das cidades brasileiras e o nível de precariedade dos setores sócio-econômicos mais pauperizados da população;

c) a espacialidade, característica do processo de urbanização ocorridos no país, que implica maiores dificuldades físicas, financeiras e legais para a implantação de redes nas periferias brasileiras;

d) a perversa degradação ambiental e pobreza urbana que revela a necessidade de integração setorial e de articulação institucional de políticas públicas. ${ }^{29}$

Percebemos que a preocupação com os aspectos regionais está entre as metas de um sistema integrado de prestação de serviços públicos, principalmente em matéria de saneamento, transporte e habitação e ocupação do solo urbano. Devem ser implementadas por políticas públicas integradas.

Se não houver investimentos em habitação e saneamento ambiental, gastar-se-á mais em áreas sub-habitadas, cuja melhoria, a despeito de qualquer atitude criativa do poder público, será mais dispendiosa e irremediável. Da mesma forma, não se investindo em saneamento, gastar-se-á mais em saúde e em políticas regionais ambientais de combate à degradação decorrente da presença humana. Se não houver investimento em saneamento nestas áreas, setores que sempre necessitam de recursos públicos, mais dificultosa será a tarefa de encontrar soluções para erradicar tais desigualdades. Regiões de alta concentração demográfica, espalhadas pelo Brasil, reúnem problemas que se associam à gestão da água e seus serviços derivados.

Eventuais riscos, derivados de eventos extremos, como as secas, as inundações recorrentes ou os acidentes nas infra-estruturas hidráulicas, exigem medidas preventivas, em situação de constante alerta, a fim de combater possíveis calamidades públicas.

\section{O Ordenamento jurídico da metrópoles e federalismo}


O ordenamento constitucional estabeleceu a possibilidade, ou melhor, reconheceu a existência de criação, na esfera dos estados-membros, das regiões com elevado índice de conurbação, as regiões metropolitanas, aglomerações urbanas e microrregiões, que serão definidas a seguir.

As regiões metropolitanas eram previstas na Constituição de 1967/69, cuja Lei Complementar 14/73, criou as regiões metropolitanas de São Paulo, Belo Horizonte, Porto Alegre, Salvador, Curitiba, Belém e Fortaleza. A reestruturação federativa operada pela Constituição atual deixou a responsabilidade pela implementação e definição destas e dos respectivos serviços aos estados-membros.

Estas regiões são criadas por lei complementar estadual, nos termos do art. 25 , $\S 3^{\circ}$ da Constituição Federal, que deverão delimitar as respectivas funções de interesse comum, integrando municípios limítrofes. Esta integração é compulsória para que possam ser realizadas estas funções de interesse comum, que na realidade possuem um alto teor de interesse local. Não há uma figura político-administrativa nova no ordenamento jurídico, mas um espaço intermediário para tratamento de determinados serviços públicos.

Logo, os requisitos constitucionais encontram no processo legislativo e na iniciativa do projeto de lei pela entidade estadual.

A região metropolitana significa comunhão de interesse entre estado e municípios, sendo necessário à existência de um conjunto de municípios ${ }^{30}$. É admitir a figura da cidade regional, da reunião de municípios sem seus respectivos limites geográficos. Caso ocorresse uma fusão entre estes municípios, não haveria necessidade de instituir-se tal região, uma vez que o impacto de qualquer intervenção urbana e ambiental seria suportado apenas por um ente municipal. Significa a existência de um corpo jurídico-administrativo territorial, cuja formatação jurídica veremos a seguir.

Envolve a participação de todos os municípios interessados, quebrando a visão de uma separação de competência e de atuações exclusivas. Esta visão inaugura um federalismo de cooperação, com interpretações sistematizadas das competências em matéria urbana. Esta competência está inserida num contexto de maior ou menor impacto de seu exercício. Assim, na competência metropolitana temos o interesse extralocal demonstrado na medida em que os serviços públicos nela circunscritos repercutem em outros municípios.

Ao contrário da Constituição anterior, na qual a matéria referente às regiões metropolitanas era tratada no art. 164 da Emenda Constitucional n. 1/69 e nos dispositivos da Ordem Econômica, ${ }^{31}$ sob o prisma constitucional atual, este tema deslocou-se para o Capítulo referente à Organização do Estado, caracterizando o nítido objetivo do legislador constituinte originário em tratar esta questão dentro da estrutura organizacional e administrativa do Estado brasileiro.

O principal lapso federativo da Constituição atual concentra-se em deixar ao plano regional o conceito de metrópoles nacionais, cujos territórios concentram a maior parte da economia nacional, sediam empresas, produzem e incrementam o PIB, produzem industrialmente, sem uma legislação uniforme, sem a sugestão de modelos de gestão e de ações prioritárias nestas regiões. ${ }^{32}$ A despeito disto, à União cabe formular inúmeras políticas ou diretrizes gerais em habitação, saneamento, transportes, recursos hídricos, conforme os artigos 21 e 182.

Coincidentemente, desde um pouco antes da instalação e promulgação da Constituinte, os sistemas federais de promoção do desenvolvimento urbano sofrem uma redução em suas atividades, nitidamente em 1986, com a extinção do BNH, principal 
agente empreendedor em matéria de saneamento, tendo sido transferido todo seu passivo e ativo à $\mathrm{CEF}{ }^{33}$

A Constituição Federal, mantendo dispositivo semelhante ao contido nas constituições anteriores, permitiu aos Estados a criação de regiões metropolitanas para planejar e regulamentar serviços públicos essenciais, art. $25, \S 3^{\circ}$, recepcionando, da mesma forma, a Lei Complementar 27, de 03/11.75, que alterou a Lei Complementar 14 de $8 / 6 / 73^{34}$.

Esta Lei Complementar revogada definia como serviços metropolitanos: saneamento básico (águas e esgotos e limpeza urbana), transportes e sistema viário, aproveitamento de águas e controle ambiental, uso do solo metropolitano e produção e distribuição de gás canalizado.

É região metropolitana ${ }^{35}$ o agrupamento de municípios limítrofes que assuma destacada expressão nacional, em razão de elevada densidade demográfica, significativa conurbação e de funções urbanas e regionais com alto grau de diversidade, especialização e integração sócio-econômica, exigindo planejamento integrado e ação conjunta permanente dos entes públicos nela atuantes.

Aglomeração urbana é o agrupamento de municípios limítrofes que apresente relação de integração funcional de natureza econômico-social e urbanização contínua entre dois ou mais municípios, ou manifesta tendência nesse sentido, que exija planejamento integrado e recomende ação coordenada dos entes públicos nela atuantes.

Microrregião é o agrupamento de Municípios limítrofes que apresentem, entre si, relações de interação funcional de natureza físico-territorial, econômico-social e administrativa, exigindo planejamento integrado com vistas a criar condições adequadas para o desenvolvimento e integração regional.

Lei complementar estadual conterá as normas necessárias à definição destes serviços públicos, sem excluir a atuação dos municípios e sem aniquilar a autonomia municipal.

A instituição de regiões metropolitanas é importante para a racionalização dos serviços comuns, envolvendo economia e cooperação mútua entre as esferas estadual e municipal, sem esquecer a imperiosa atuação do ente federal no fomento de medidas que reduzam o impacto do adensamento territorial na vida dos seus nacionais.

Estas regiões visam a um planejamento organizacional de execução destes serviços essenciais. $^{36} \mathrm{O}$ planejamento não se confunde com execução, nem tão pouco com intervenção em esfera de competência diversa. O crescimento populacional de cidades em função de outras cidades cria um fenômeno que é a falta de precisão entre os limites de atuação de uma prefeitura nas áreas dos municípios mais próximos.

É evidente que o impacto de determinadas ações não podem ser interpretados num enfoque de atuação federativa tão restrita. Privilegiar a competência local para serviços que tenha impacto territorial considerável é imaginar que a solução de qualquer indefinição constitucional de repartição pode ser resolvida com base em suposta competência residual local. Certamente, não é isto que se quer. A relação entre os vários, e complexos, serviços públicos metropolitanos inclui temas como, saneamento, urbanização, engenharia de tráfego, proteção do meio ambiente, gestão de águas urbanas e gerenciamento hídrico já fora descrito. A pergunta a ser feita é: qual o impacto de determinado serviço em relação a toda extensão territorial, ou mesmo na qualidade de vida da comunidade?

Podemos ter mente que algumas destas atribuições nestas regiões conurbadas podem e devem ser prestadas de forma compartilhada, conforme os ditames 
constitucionais. Na estrutura das grandes cidades e nas metrópoles, a importância de se entender as cidades a partir do impacto dos serviços, ou de sua má prestação, faz o espaço urbano, local, e interurbano, de suma importância para toda a coletividade de um país. internacionais. ${ }^{37}$

A existência da metrópole decorre de questões econômicas nacionais e

O espaço metropolitano é importante para o desenvolvimento do País, impondo aos entes federativos ${ }^{38}$ ações conjuntas, coordenadas em função de um interesse que extrapola a própria urbe. $^{39}$

Os problemas enfrentados pelas metrópoles têm impacto nacional, por concentrar a maior parte das corporações e serviços de interesse da União, configurando um centro de investimento e acumulação de capital, $^{40}$ trazendo para o debate da questão as ações conjuntas, evidenciando a ação cooperada entre poderes públicos locais, estaduais e principalmente o federal.

Convém mencionar que os elementos que configuram a existência da região metropolitana podem ser descaracterizados em determinado momento, seja em decorrência de um fenômeno inverso, de um improvável esvaziamento metropolitano, da fusão de todos municípios envolvidos, ou mesmo no caso de mudança na personalidade jurídica de determinado ente federativo.

\section{Conclusão}

O estudo das soluções para as várias crises vinculadas à prestação de serviços públicos e desenvolvimento econômico sustentável passa pelo enfoque do desenvolvimento das regiões metropolitanas

A ação dos agentes federais, regulatórios e operacionais, não podem esperar a convocação dos gestores estaduais e municipais, aguardando o momento em que as distorções já existentes desencadeiem outras crises sociais que não existiam ou que estavam sufocadas.

Se, por um lado, as regiões metropolitanas são espaços reconhecidas por legislações estaduais, por outro raciocínio temos a existência de competências federais nos mais diversos aspectos urbanos. Não seria um exagero dizer que a União tem em seu poder os instrumentos de gestão mais eficazes para garantir políticas públicas que solucionem, com maior agilidade, as questões abordadas neste breve estudo.

\footnotetext{
${ }^{1}$ Art. $1^{\mathrm{o}}$ da Constituição Francesa.

${ }^{2}$ BARACHO, José Alfredo de Oliveira. Teoria geral do federalismo. Rio de Janeiro: Forense, 1986 , p. 54.

${ }^{3}$ As diversas formas de Estado variam entre si em virtude do número de pólos formais de poder político e dos vínculos estabelecidos entre esses pólos formais. O conceito de federação se funda na coexistência de diversas ordens político-jurídicas autônomas sobre um mesmo território.

${ }^{4}$ BERCOVICI, Gilberto. Desigualdades regionais, estado e constituição. São Paulo: Max Limonad, 2003, p. 145. DALLARI, Dalmo de Abreu. O estado federal. São Paulo: Ática, 1986, p. 50-51. Aqui não podemos concordar com o mestre Baracho, na tentativa de justificar uma teoria geral do federalismo.

5 “La federación es una union permanente, basada en libre convenio, y al servicio del fin común de la autoconservación de todos los miembros, mediante la cual se cambia el total status político de cada uno de los miembros en atención al fin común. (...) El pacto federal es un pacto de singular especie, un pacto constitucional. Su acuerdo es un acto de Poder constituyente. Su contenido es, al mismo tiempo, contenido de
} 
la Constitución federal y un elemento de la Constitución de cada uno de los Estados-miembros”.. SCHMITT, Carl. Teoría de la constitución. 3. ed. Madrid: Alianza Editorial, 2001, p. 348-350.

${ }^{6}$ BERCOVICI, Gilberto. Op. Cit., p. 147-149.

${ }^{7}$ BARACHO, José Alfredo de Oliveira. Op. Cit., p. 11.

${ }^{8}$ FERNANDES, Nelson da Nóbrega. Globalizacion y crise del federalismo en Brasil. Disponível em: www.esaf.fazenda.gov.br/parcerias/ue/cedoc-ue/ leituras-complementares/a2-integracao-economica.html . Acessado em 10/06/2005.

${ }^{9}$ De acordo com SCHWARTZ, Bernard. "Sua preocupação dominante foi assegurar que o Governo nacional que estavam criando não fosse tão poderoso que, na prática, tragasse os estados dos quais se comporia a Nação. Eles procuraram conseguir isto limitando o Governo Federal a uma lista específica de poderes enumerados essenciais a seu funcionamento efetivo, ao mesmo tempo em que reservavam todo o resto de autoridade aos estados, que deveriam continuar inalterados como soberanias separadas, exceto quanto a quaisquer poderes que houvessem cedido à Nação". SCHWARTZ, Bernard. O federalismo norte-americano atual: uma visão contemporânea. São Paulo: Forense Universitária, 1986, p. 9.

${ }^{10}$ É claro que o desenvolvimento histórico e jurídico norte-americano está vinculado a adaptação do governo ao ambiente externo e a evolução do capitalismo. É ilustrativa a diferença de enfoque entre a os Estados Unidos e a Alemanha no que diz respeito ao monopólio. Nos Estados Unidos surgiram leis antitruste que objetivavam combatê-los. Na Alemanha, a jurisprudência consagrou que a formação oligopolista era lícita, e daí defluia uma concorrência perfeita. A explicação é que a Alemanha, na época, necessitava fortalecer-se economicamente, incentivando os conglomerados de empresas, para fazer face ao poderio inglês. STRECK, Lênio Luiz. MORAIS, José Luis Bolzan de. Ciência política e teoria geral do estado. 3. ed. Porto Alegre: Livraria do Advogado Editora, 2003, p. 65.

${ }^{11}$ MAGAlHÃES, José Luís Quadro. Pacto federativo. Belo Horizonte: Mandamentos, 2000, p.52.

${ }^{12}$ Este case diz respeito a constitucionalidade da incorporação pelo Congresso Federal, em 1816, do Banco dos Estados Unidos, que funcionava como depositário de reservas governamentais e que estava autorizado a imprimir notas bancárias. A Constituição americana não definia expressamente este poder ao Congresso. SCHWARTZ, Bernard. Op. Cit., p. 14-15.

${ }^{13}$ Até 1937, a Suprema Corte decidia de modo favorável ao laissez-faire econômico. O caso mais famoso, sobre direitos trabalhistas, foi o Lochner v. New York, de 1905.

${ }^{14}$ SCHWARTZ, Bernard. Op. Cit., p. 21.

${ }^{15}$ Ibidem, p. 22.

${ }^{16}$ Ibidem, p. 44-48.

${ }^{17}$ A Suprema Corte só começou a abandonar a concepção dualista do federalismo norte-americano a partir de 1937, quando passou a reinterpretar a $10^{\text {a }}$ emenda à Constituição de 1787, que determinava que os poderes remanescentes, ou seja, os não explicitados no texto constitucional, pertenciam aos Estados ou ao povo dos Estados Unidos, de modo que não mais se exigisse a separação completa entre os poderes federais e estaduais. Dessa maneira, as características formais do federalismo norte-americano não foram modificadas. O que mudou foi o entendimento da Suprema Corte sobre a interpretação do sistema federal. SCHWARTZ, Bernard. Op. Cit., p. 48-55. BERCOVICI, Gilberto. Dilemas do estado federal brasileiro. Porto Alegre: Livraria do Advogado, 2003, p. 21-22.

${ }^{18}$ BERCOVICI, Gilberto. Dilemas do estado federal brasileiro. Op. Cit., p. 31.

${ }^{19}$ Ibidem, p. 42-43.

${ }^{20}$ BERCOVICI, Gilberto. Desigualdades regionais, estado e constituição. São Paulo: Max Limonad, 2003, p. 150-151. Esta posição é rechaçada por Gilberto Bercovici que diz ser um exagero denominar o sistema federalista de 1988 como um federalismo estadual.

${ }^{21}$ BERCOVICI, Gilberto. Dilemas do estado federal brasileiro. Op. Cit., p. 56. Em nenhuma concepção doutrinária o federalismo é entendido como oposto à unidade do Estado. Ao contrário, a finalidade do federalismo é a unidade, respeitando e assimilando a pluralidade. BERCOVICI, Gilberto. Desigualdades regionais, estado e constituição. Ressaltando que a autonomia não se opõe à unidade, mas à centralização em determinados órgãos ou setores do Estado. São Paulo: Max Limonad, 2003, p. 147.

${ }^{22}$ BERCOVICI, Gilberto. Desigualdades regionais, estado e constituição. São Paulo: Max Limonad, 2003, p. 156-157.

${ }^{23}$ DALLARI, Dalmo de Abreu. O Estado Federal. São Paulo: Ática, 1986, p. 69-70.

${ }^{24} \mathrm{Na}$ constituição anterior os municípios sequer contavam com um capítulo exclusivo, sendo tratados juntamente com os Estados. 
${ }^{25}$ A prevalência do direito federal sobre o direito estadual e municipal não é um problema de competência entre a União e os demais entes federados, más uma forma de solucionar eventuais conflitos oriundos da repartição de competências, determinando qual o direito válido, que na Constituição de 1988 é definida no art. $24, \S 4^{\circ}$.

${ }^{26}$ BERCOVICI, Gilberto. Desigualdades regionais, estado e constituição. Max Limonad, 2003, p. 152-153. ${ }^{27}$ BERCOVICI, Gilberto. Desigualdades regionais, estado e constituição. Max Limonad, 2003, p. 152-153154.

${ }^{28}$ BRASIL. Ministério do Meio Ambiente/ IBAMA/ Consórcio Parceria 21. Cidades sustentáveis: subsídios à elaboração de Agenda 21 brasileira. Brasília, 2000, p 43.

${ }^{29}$ Ibidem, p. 47-48.

${ }^{30} \mathrm{O}$ interesse metropolitano é uma parcela dos respectivos interesse das unidades político-administrativas envolvidas na promoção dos serviços comuns. ALVES, Alaor Caffé apud SILVA, José Afonso. Direito urbanístico brasileiro. 2. ed. São Paulo: Malheiros, 1995, p. 141.

${ }^{31}$ ALVES, Alaor Caffé. Regiões metropolitanas, aglomerações urbanas e microrregiões: novas dimensões constitucionais da organização do estado brasileiro. In Temas de direito ambiental e urbanístico. Advocacia Pública \& Sociedade, São Paulo, ano II, n. 3, p. 17, 1998.

${ }^{32}$ Por concentrar a maior parte das sedes sociais das maiores corporações, a metrópole transforma-se, por excelência, em centro de gestão do território, ou seja, em centro de investimento e acumulação de capital, centro privilegiado do ciclo de reprodução do capital, onde se dá a gestão do processo de criação do valor e criação, circulação e apropriação da mais-valia em amplo espaço geográfico. CORREA, Roberto Lobato. Metrópoles, corporações e espaço: uma introdução ao caso brasileiro. In Brasil: questões atuais de reorganização do território. CASTRO, Iná Elias; GOMES, Paulo César Costa; CORREA, Roberto Lobato. Metrópoles, corporações e espaço: uma introdução ao caso brasileiro. In: Brasil: questões atuais de reorganização do território. Rio de Janeiro: Bertrand Brasil, 1996, p.68-69.

${ }^{33} \mathrm{O}$ saneamento básico foi a porta pela qual o BNH começou a aplicar no desenvolvimento urbano; o que já se propunha pela lei de sua criação. Em 1971, foi criado o Plano Nacional de Saneamento - PLANASA -, e já em 1969, o BNH é autorizado a aplicar recursos do FGTS nos sistemas de abastecimento de água e esgoto. DAMIANI, Amélia Luisa. A crise da cidade: os termos da urbanização. In. DAMIANI, Amélia Luisa; CARLOS, Ana Fani Alessandri; SEABRA, Odette Carvalho Lima. O espaço no fim de século. 2 ed. São Paulo: Contexto, 2001, p.123.

${ }^{34}$ Os serviços de distribuição de gás canalizado, independente de lei complementar e de sua prestação em região metropolitana, por dispositivo constitucional expresso, é matéria de competência estadual, art. 25, § $2^{\circ}$ da CF.

${ }^{35}$ Diogo de Figueiredo Moreira Neto, em estudo após o processo de fusão entre os Estados da Guanabara e Rio de Janeiro, descreve as regiões metropolitanas constituem uma realidade que não podem estar desvinculadas de um planejamento regional, sendo suas tarefas grandes demais para um Estado-membro assumir. Introdução ao direito ecológico e ao direito urbanístico. Rio de Janeiro: Forense, 1977, p. 120121.

${ }^{36}$ Planejamento é um processo técnico instrumental para transformar a realidade existente no sentido de objetivos previamente estabelecidos. SILVA, José Afonso da, apud MEDAUAR, Odette. Estatuto de cidade. Lei 10.257, de 10.07.2001: comentários. São Paulo: Revista dos Tribunais, 2004, p. 46.

${ }^{37}$ Milton Santos descreve que as grandes cidades destacam-se pela complexidade maior de suas atividades, denominando estas como metrópoles globais, incluindo nestas cidades do Terceiro Mundo, cada qual com situações particulares, em função da modernização incompleta. SANTOS, Milton. Por uma economia política da cidade. São Paulo: EDUC, 1994, p. 21.

${ }^{38}$ José Nilo de Castro, ao se referir ao papel dos municípios no direito brasileiro, aborda que estes não são componentes da Federação, pois não há, ainda que se reconheça sua importância e sua autonomia política, capacidade para que este apresente características de entidade federativa, como representação no Senado, Poder Judiciário próprio, Tribunal de Contas (salvo Rio e São Paulo); Sem estados-membros não há federação, sendo que o mesmo não se pode afirmar sobre os municípios. CASTRO, José Nilo de. Direito positivo municipal. Belo Horizonte: Del Rey, 1999, p. 53.

${ }^{39}$ Na metropolização tem-se a concentração massiva de população, produção e consumo ao redor de algumas poucas grandes cidades. Dados recentes indicam que aproximadamente $45 \%$ da população urbana vivem hoje em nove dessas grandes cidades - as Regiões Metropolitanas -, que no seu conjunto cobrem menos de $1 \%$ do território nacional. Tal concentração de pessoas e atividades econômicas tem trazido conseqüências e 
problemas graves, assim como um nível de qualidade ambiental muito baixo. FERNANDES, Edésio (Org). Direito urbanístico. Belo Horizonte: Del Rey, 1995. p. 208.

${ }^{40}$ CORREA, Roberto Lobato. Metrópoles, corporações e espaço: uma introdução ao caso brasileiro. In: CASTRO, Iná Elias; GOMES, Paulo César Costa; CORREA, Roberto Lobato. Brasil: questões atuais da reorganização do território. Rio de Janeiro: Bertrand Brasil, 1996, p. 68.

\section{Referência:}

ALVES, Alaor Caffé. Regiões metropolitanas, aglomerações urbanas e microrregiões: novas dimensões constitucionais da organização do estado brasileiro. In Temas de direito ambiental e urbanístico. Advocacia Pública \& Sociedade, São Paulo, ano II, n. 3, p. 17, 1998.

BARACHO, José Alfredo de Oliveira. Teoria geral do federalismo. Rio de Janeiro: Forense, 1986.

BERCOVICI, Gilberto. Desigualdades regionais, estado e constituição. São Paulo: Max Limonad, 2003.

. Dilemas do estado federal brasileiro. Porto Alegre: Livraria do Advogado, 2004.

BRASIL. Ministério do Meio Ambiente/ IBAMA/ Consórcio Parceria 21. Cidades sustentáveis: subsídios à elaboração de Agenda 21 brasileira. Brasília, 2000.

CARLOS, Ana Fani Alessandri; SEABRA, Odette Carvalho Lima. O espaço no fim de século. 2. ed. São Paulo: Contexto, 2001.

CASTRO, Iná Elias; GOMES, Paulo César Costa; CORREA, Roberto Lobato. Metrópoles, corporações e espaço: uma introdução ao caso brasileiro. In: Brasil: questões atuais de reorganização do território. Rio de Janeiro: Bertrand Brasil, 1996.

CASTRO, José Nilo de. Direito positivo municipal. Belo Horizonte: Del Rey, 1999.

CORREA, Roberto Lobato. Metrópoles, corporações e espaço: uma introdução ao caso brasileiro. In: FERNANDES, Edésio (Org). Direito urbanístico. Belo Horizonte: Del Rey, 1995.

FERNANDES, Nelson da Nóbrega. Globalizacion y crise del federalismo en Brasil. Disponível em: <www.esaf.fazenda.gov.br/parcerias/ue/cedoc-ue/ leiturascomplementares/a2-integracao-economica.html>. Acessado em 10 junho 2005.

LEVI, Lucio. Federalismo. In: BOBBIO, Norberto; MATTEUCCI, Nicola; PASQUINO, Gianfranco. Dicionário de política. 5. ed. Brasília: Editora UNB, 2000.

MAGAlHÃES, José Luís Quadro. Pacto federativo. Belo Horizonte: Mandamentos, 2000. 
MOREIRA NETO, Diogo de Figueiredo. Introdução ao direito ecológico e ao direito urbanístico. Rio de Janeiro: Forense, 1977.

SCHMITT, Carl. Teoría de la constitución. 3. ed. Madrid: Alianza Editorial, 2001.

SCHWARTZ, Bernard. O federalismo norte-americano atual: uma visão

contemporânea. São Paulo: Forense Universitária, 1986.

SANTOS, Milton. Por uma economia política da cidade. São Paulo: EDUC, 1994.

SILVA, José Afonso. Direito urbanístico brasileiro. 2. ed. São Paulo: Malheiros, 1995.

SILVA, José Afonso da, apud MEDAUAR, Odette. Estatuto de cidade. Lei 10.257, de 10.07.2001: comentários. São Paulo: Revista dos Tribunais, 2004.

STRECK, Lênio Luiz. MORAIS, José Luis Bolzan de. Ciência política e teoria geral do estado. 3. ed. Porto Alegre: Livraria do Advogado Editora, 2003.

Informações bibliográficas:

Conforme a NBR 6023:2002 da Associação Brasileira de Normas Técnicas (ABNT), este texto científico publicado em periódico eletrônico deve ser citado da seguinte forma: SANTOS, Benevenuto . Federalismo e Desenvolvimento Urbano. Cadernos UniFOA , Volta Redonda, ano 1, $\mathrm{n}^{\circ}$. 1, jul. 2006. Disponível em:

$<$ http://www.unifoa.edu.br/pesquisa/caderno/edicao/01/55.pdf> 